\title{
HEN VÀ COVID-19 TỔNG HợP CÁC QUAN ĐIỂM VÀ KHUYẾN CÁO CHUNG
}

Trần Anh Tuấn

Khoa Hô hấp, BV Nhi Đồng 1

\section{1. ĐẶT VẤN ĐỀ}

Từ tháng 12/2019, viêm đường hô hấp do Coronavirus chủng mới (SARS-CoV2) đã được báo cáo đầu tiên ở Vũ Hán (Trung Quốc). Bệnh nhanh chóng lay truyền đến nhiều vùng khác nhau của Trung Quốc, sau đó đến hàng loạt quốc gia trên thế giới. Ngày 11/02/2020, TCYTTG chính thức đặt tên là COVID-19, và sau đó ngày 11/03/2020 đã được công bố là đại dịch toàn cầu.

Ngay từ thời gian đầu, bệnh nhân hen là một trong những đối tượng được quan tâm đặc biệt do hen chính là bệnh hô hấp mạn tính phổ biến hàng đầu. Thật vậy, bệnh nhân hen, nhất là hen nặng, đứng trước nguy cơ dễ nhiễm SARS-CoV-2, dễ có biến chứng nặng và nguy cơ tử vong cao trong thời kỳ đại dịch COVID-19.

Nhiều Tổ chức Y tế, Hội chuyên ngành trên thế giới đã nhanh chóng công bố những khuyến cáo dành cho bệnh nhân hen:TCYTTG, CDD, ATS, BTS, Canada, Úc, GINA, ARIA, EAACI, ...

Chúng tôi xin tổng hợp những quan điểm và một số khuyến cáo chung dành cho bệnh nhân hen trong thời kỳ đại dịch COVID-19 này.

\section{NộI DUNG}

2.1. Bệnh nhân hen có phải là đối tượng nguy cơ cao nhiễm SARS-CoV-2?

Do SARS-CoV-2 là virus gây bệnh đường hô hấp nên đúng là bệnh nhân hen bị đặt trước nguy cơ trong thời kỳ đại dịch COVID-19.

Tuy vậy, cho đến nay lại có ít dữ liệu cho thấy hen thật sự là yếu tố nguy cơ nhiễm COVID-19 hay bệnh hen sẽ tiến triển nặng khi nhiễm SARSCoV2. Hen cũng không cho thấy là bệnh đồng mắc quan trọng của COVID-19 cũng như không phải là yếu tố nguy cơ biến chứng, tiên lượng nặng ở bệnh nhân COVID-19.

Các dữ kiện ban đầu từ Trung Quốc, Hàn Quốc không cho thấy hen là yếu tố nguy cơ mạnh của COVID-19 nặng. Trong một nghiên cứu ban đầu ở 140 bệnh nhân COVID-19 và sau đó trong một nghiên cứu với cỡ mẫu lớn hơn với 1.099 người nhập viện vì COVID-19 ở Trung Quốc, các tác giả lại không ghi nhận có bất kỳ bệnh nhân hen nào. Dữ liệu thu nhận được tại Hàn Quốc cũng không cho thấy hen là yếu tố nguy cơ cao của COVID-19 $[9,10,15]$.

Bên cạnh nguy cơ trực tiếp từ việc nhiễm bệnh COVID-19, bệnh nhân hen cũng có thể có nguy cơ bị kích phát cơn hen khi nhiễm Coronavirus. Tuy các chủng Coronavirus thông thường lưu hành trong cộng đồng cũng đã từng được ghi nhận như là nguyên nhân gây khởi phát cơn hen, nhưng trong các đại dịch do các chủng Coronavirus mới trước đó (SARS-CoV và MERS-CoV) không cho thấy các chủng này có kết hợp với cơn hen cấp.

Nhận bài: 20-9-2020; Chấp nhận: 5-10-2020 
Ngoài ra, không có bằng chứng cho thấy bệnh nhân hen đang điều trị lâu dài bằng ICS sẽ bị tăng nguy cơ nhiễm COVID-19 hơn.

Nhưng dù sao vẫn bắt buộc phải có kế hoạch giúp bệnh nhân hen kiểm soát tốt bệnh hen và giới hạn tối đa khả năng lên cơn hen nặng, cũng như cần tuân thủ thật nghiêm túc các biện pháp phòng ngừa COVID-19 nói chung.

\section{KHUYẾN CÁO CHUNG}

Bệnh nhân hen cần phải có biện pháp quản lý phù hợp để đảm bảo hen được kiểm soát tốt và hạn chế khả năng có cơn hen cấp nặng

2.2. Chẩn đoán và đánh giá hen trong giai đoạn đại dịch COVID-19

Các thầy thuốc lâm sàng cần lưu ý rằng có thể có sự chồng lắp giữa các triệu chứng của COVID-19 với viêm mũi dị ứng, cúm, nhiễm virus đường hô hấp trên và hen trong giai đoạn sớm. Chỉ khi bệnh tiến triển muộn hơn thì các triệu chứng COVID-19 mới rõ ràng hơn [5].

Thật vậy, bệnh nhân COVID-19 cũng có thể có biểu hiện như hen (ho, khó thở). Tuy nhiên, nếu bệnh nhân sốt cao, mệt mõi, thay đổi khướu giác - vị giác thì lại gợi ý nhiều cho nhiễm SARS-CoV2.

Thăm dò chức năng hô hấp được xem là tiêu chuẩn vàng trong chẩn đoán hen và được khuyến cáo thường quy trong chẩn đoán, đánh giá, theo dõi hen. Tuy nhiên, trong thời kỳ COVID-19, các khuyến cáo mới đây của GINA, NHS, CDC, Uptodate 2020 đều thống nhất như sau: Chỉ trừ trường hợp thật cần thiết do kết quả chức năng hô hấp sẽ có ảnh hưởng trực tiếp đến xử trí cấp cứu, còn thì không nên thực hiện thăm dò chức năng hô hấp trong giai đoạn đại dịch COVID-19 do nguy cơ làm phát tán SARS-CoV2 (do gây ho, tạo hạt khí dung khi tiến hành).

Ngoài ra, cần tránh thực hiện test giãn phế quản hay kích thích phế quản bằng cách phun khí dung mà nên thay bằng sử dụng MDI với buồng đệm.

Khi cần thực hiện thăm dò chức năng hô hấp, cần lưu ý tuân thủ biện pháp kiểm soát nhiễm trùng, trong đó cung cấp các biện pháp phòng hộ cá nhân cho nhân viên và người hiện diện ở nơi đo. Các kỹ thuật viên thực hiện thăm dò chức năng hô hấp trong thời gian đại dịch cần được trang bị khẩu trang N95 hay khẩu trang có lọc khí (PAPR: powered air purifying respirators). Cũng lưu ý tránh để nhiều người hiện diện, chờ đợi cùng một lúc trong phòng thăm dò chức năng hô hấp.

Tạm hoãn các xét nghiệm dị ứng như test lẩy da và các test thử thách trong giai đoạn dịch COVID-19. Nếu thật sự cần, khuyến cáo có thể xem xét thay bằng định lượng lgE đặc hiệu.

\subsection{Xử trí cơn hen trong thời kỳ đại dịch} COVID-19 như thế nào?

Nói chung nguyên tắc xử trí cơn hen không thay đổi nhưng cần lưu ý:

Khuyến cáo sử dụng thuốc đồng vận beta dưới dạng MDI với buồng đệm hoặc dụng cụ hít bột khô (turbuhaler, diskus) hơn là dạng phun khí dung.

Trong giai đoạn đại dịch chỉ nên dùng khí dung salbutamol khi không có giải pháp khác.

Ở trẻ > 12 tuổi và người lớn, nên sử dụng ICSformoterol dạng hít cho cả hai mục đích duy trì và cắt cơn như khuyến cáo mới đây của GINA 2019-2020. 
Nếu có chỉ định corticosteroid đường toàn thân thì vẫn cần phải sử dụng trong thời gian ngắn hạn để tránh cơn hen diễn tiến xấu đi.

Ngay cả khi bệnh nhân đã xác định nhiễm COVID-19 bị lên cơn hen, cũng cần tuân thủ các hướng dẫn điều trị cơn hen hiện hành cho đến khi có các khuyến cáo khác rút ra từ các nghiên cứu khoa học (34).

Bệnh nhân cần được cung cấp đầy đủ thuốc cắt cơn và phòng ngừa hen để đủ dùng trong thời gian cách ly xã hội và thăm khám khó khăn cùngcác dụng cụ hít như buồng đệm, mặt nạ phù hợp (tốt nhất nên dự trù cho ít nhất 1 tháng).

Cần cung cấp và hướng dẫn bệnh nhân thực hiện bảng kế hoạch hành động (KHHĐ), nhất là trong giai đoạn giãn cách xã hội, hạn chế đi khám tại bệnh viện. Sử dụng bảng KHHĐ còn giúp bệnh nhân tránh việc phải đến bệnh viện khi không thật sự cần thiết nhằm tránh nguy cơ lây nhiễm COVID-19 từ bệnh nhân khác.

Khi có biểu hiện lên cơn hen, bệnh nhân cần sử dụng thuốc theo bảng KHHĐ và tiếp xúc với bác sĩ dưới hình thức tư vấn từ xa (qua điện thoại, video call,...) hơn là thăm khám trực tiếp.

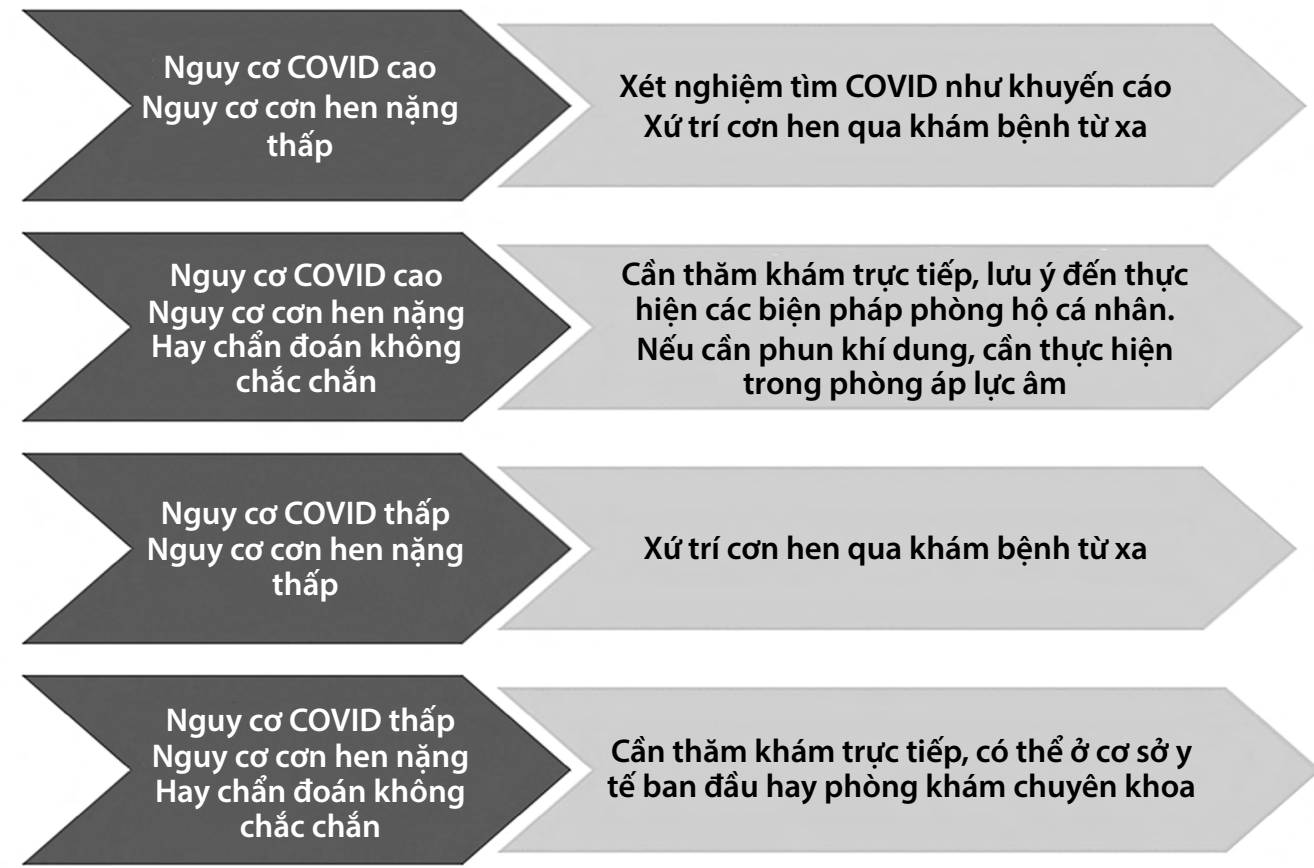

Lưu đồ 1. Tiếp cận bệnh nhân có triệu chứng cơn hen trong giai đoạn đại dịch COVID-19

(Nguồn: Special Article: COVID-19: Pandemic Contigency Planning for the Allergy and Immunology Clinic) [13]

2.4. Khuyến cáo điều trị dự phòng hen trong thời kỳ CoVID-19:

Tránh các yếu tố khởi phát cơn hen:

Không hút thuốc hay xông hơi tại nhà

Lau và sát trùng thường xuyên các bề mặt thường tiếp xúc (bàn, nắm cửa, công tắc đèn, quầy, điện thoại, bàn phím, bồn cầu, vòi nước,...)
Tránh các thuốc sát trùng, tẩy rửa có thể làm khởi phát cơn hen.

Sử dụng corticoid hít (ICS) trong thời kỳ COVD-19:

Vấn đề đặt ra là ICS có làm suy giảm miễn dịch và tăng nguy cơ nhiễm COVID-19 hay không?. Hiện nay không có bằng chứng là ICS làm tăng nguy cơ nhiễm COVID-19. 
Như đã nêu trên, điều quan trọng nhất trong giai đoạn đại dịch là phải duy trì kiểm soát hen. Do vậy, không được ngưng ICS trong thời kỳ này vì điều này sẽ làm cho bệnh nhân hen có nhiều nguy cơ lên cơn hen, không chỉ do nhiễm SARS-CoV-2 mà còn do nhiễm virus hô hấp khác cũng như phơi nhiễm với các dị nguyên khác (như phấn hoa chẳng hạn). Và khi lên cơn hen, bệnh nhân cần phải đi thăm khám, cấp cứu tại các cơ sở y tế, bệnh viện - điều này mới khiến cho bệnh nhân dễ nhiễm SARS-CoV-2 từ người bệnh khác chứ không phải do chính nguy cơ đến từ bệnh hen.

Do vậy, tất cả các khuyến cáo đều nhấn mạnh: bệnh nhân cần tiếp tục dùng ICS, ICS-LABA để dự phòng hen nếu được chỉ định.

Không giảm bậc điều trị trong giai đoạn đại dịch COVID-19, trừ khi bệnh nhân có điều kiện thuận lợi rõ ràng, cân nhắc kỹ lợi ích/nguy cơ, và bệnh nhân có cơ hội tiếp cận y tế dễ dàng.

Bệnh nhân hen kèm viêm mũi dị ứng cũng cần tiếp tục sử dụng corticoid xịt mũi như bác sĩ chỉ định.

\section{Sử dụng corticoid uống trong hen nặng:}

Bệnh nhân hen nặng cần điều trị dài ngày bằng corticoid uống cũng cần tiếp tục với liều thấp nhất có thể để tránh nguy cơ cơn hen nặng. Mặt khác, nếu được chỉ định corticoid vì hen nặng thì không nên ngưng corticoid uống vì "sợ" do nguy cơ tình trạng hen sẽ trở nên xấu hơn. Khi này, ngoài việc tính mạng có thể bị đe dọa do hen xấu đỉ, bệnh nhân còn có nguy cơ lây nhiễm COVID-19 khi phải nhập viện trong thời kỳ đại dịch.

\section{Điều trị sinh học:}

Đối với bệnh nhân hen nặng được điều trị bằng các biện pháp điều trị sinh học nhắm vào IL-5, anti-IL-4/IL-13, IgE: không có bằng chứng gợi ý đáp ứng miễn dịch với COVID-19 sẽ bị tổn hại với điều trị anti-IL5 (anti-IL5Ra), anti-IL4/IL13, anti-lgE. Do vậy, cần tiếp tục các điều trị sinh học này để bệnh nhân hen nặng được bảo vệ tối đa trong đại dịch COVID-19. Còn có khuyến cáo nên sử dụng thuốc điều trị sinh học nếu có thể để giảm thiểu nhu cầu sử dụng corticoid uống lâu dài ở bệnh nhân hen nặng.

\subsection{Vấn đề tái khám hen định kỳ}

Trong thời kỳ đại dịch COVID-19, cần hoãn các tái khám định kỳ mặt đối mặt cho các bệnh nhân:

- Với mọi mức độ nặng mà hen kiểm soát tốt trong 5-12 tháng qua.

- Hen nhẹ - trung bình.

Sử dụng hình thức tư vấn sức khỏe từ xa, đảm bảo bệnh nhân được tiếp tục chăm sóc tại nhà ngay trong điều kiện cách ly, giãn cách xã hội, hạn chế đến bệnh viện hay các cơ sở y tế.

Ưu tiên áp dụng tư vấn y tế từ xa cho bệnh nhân hen với mọi mức độ nặng mà trong 3-6 tháng qua đã:

- Cần khám cấp cứu hay nhập viện vì cơn hen

- Cần điều trị $\geq 2$ đợt corticoid uống

- Cần tăng bậc điều trị phòng ngừa hen

Đảm bảo bệnh nhân được cung cấp đủ thuốc hen trong thời gian này (ít nhất 1 tháng).

\subsection{Trang thiết bị cho bệnh nhân hen}

Bệnh nhân và người chăm sóc cần lưu ý rửa tay, rửa dụng cụ bằng dung dịch tẩy rửa đúng cách (mask, ống ngậm, buồng đệm, lưu lượng đỉnh kế).

Lưu ý không dùng chung lọ thuốc hít và dụng cụ hít với người khác. 


\section{KHUYẾN CÁO CHUNG CHO BỆNH NHÂN HEN TRONG ĐẠI DỊCH COVID-19}

Để tự bảo vệ chính bạn và giảm thiểu nguy cơ xuất hiện triệu chứng hen, cần theo các bước xử trí đơn giản như sau:

Vẫn sử dụng các thuốc kiểm soát hen hàng ngày như đã được chỉ định

- Sử dụng thuốc kiểm soát hen sẽ giúp bạn tránh nguy cơ lên cơn hen kích phát do mọi virus hô hấp, trong đó có virus COVID-19.

- Hàng ngày cần mang theo bên mình thuốc cắt cơn hen để sử dụng khi có triệu chứng cơn hen.

- Theo dõi sát các triệu chứng hen của bạn và thực hiện theo Bảng Kế hoạch hành động. Điều này sẽ giúp bạn nhận biết và xử trí các triệu chứng cơn hen, và biết khi nào cần phải tham vấn ý kiến bác sĩ hay đi khám cấp cứu khi cần.

- Hãy biết tự chăm sóc chính mình. Cần nghỉ ngơi đầy đủ, uống đủ nước và ăn thức ăn dinh dướng tốt.

- Biết gọi đến số điện thoại tư vấn hen hay đường dây nóng có liên quan khi cần.

Các bước đơn giản cần thực hiện để giảm thiểu nguy cơ nhiễm và phát tán COVID-19

- Thực hiện giãn cách xã hội/tự theo dõi/tự cách ly/cách ly theo khuyến cáo của Chính phủ.

- Rửa tay thường xuyên, đúng cách với xà phòng

- Mang khẩu trang theo đúng khuyến cáo.

- Sử dụng khăn giấy hay cánh tay để che mũi miệng khi ho, hắt hơi, không che bằng bàn tay.

- Tránh chạm tay vào mắt, mũi, miệng.

- Lau, tẩy trùng các vật dụng và bề mặt thường xuyên đụng chạm: đồ chơi, điện thoại, nắm cửa.

- Ở nhà nếu bạn bị bệnh cho đến khi không còn triệu chứng nữa.

- Tránh tiếp xúc gần gũi với người khác có vẻ không khỏe mạnh.

- Bảo đảm nắm được các thông tin chính xác về COVID-19 từ các nguồn thông tin tin cậy của chính quyền địa phương, ngành $Y$ tế, Chính phủ.

\section{TÀI LIỆU THAM KHẢO}

1. Abrams E, Jong G, Yang C. Allergy Section, Drug Therapy and Hazardous SubstancesCommittee, Respiratory Health Section, Canadian Paediatric Society (2020), Paediatric asthma and COVID-19.

2. American College of Asthma and Immunology (2020). Important information about COVID-19 for those with asthma [Available from: https://acaai.org/news/important information-about-covid-19-those-asthma].
3. Asthma Canada (2020). COVID-19 and Asthma - Health Recommendations for People with Asthma.

4. Bousquet J, Akdis C, Jutel M et al (2020). Intranasal corticosteroids in allergic rhinitis in COVID-19 infected patients: An ARIA-EAACI statement. https://doi.org/10.1111/ALL.14302.

5. British Thoracic Society (2020). Advice for Healthcare Professionals Treating People with Asthma (adults) in relation to COVID-19. 
6. Centers for Disease Control and Prevention. Addressing Therapeutic Questions to Help Coronaviurs Disease 2019 (COVID-19) Situation Canadian Physicians Optimize Asthma Management Summary [Available from: https://www.cdc.gov/ coronavirus/2019-ncov/index.html].

for their Patients During the COVID-19 Pandemic.

7. Global Initiative for Asthma (2020). Global Strategy for Asthma Management and Prevention 2020 [Available from: https://ginasthma.org].

8. Global Initiative for Asthma (2020). COVID-19: GINA Answers to Frequently Asked Questions on Asthma Management.

9. Guan WJ, Ni ZY, Hu Y et al (2020). Clinical Characteristics of Coronavirus Disease 2019 in China. N Engl J Med. 382(18): 1708-1720. doi: 10.1056/NEJMoa2002032.

10. Korean Society of Infectious Diseases (2020) Report on the epidemiological features of coronavirus disease 2019 (COVID-10) outbreak in the Republic of Korea from January 19 to March 2, 2020. J Korean Med Sci.35(10):e112.

11. Liskai C, Yang CL, Ducharme FM et al (2020), Position Statement from the Canadian Thoracic Society Asthma Assembly Steering Committee:

12. National Institute for Health and Care Excellence (2020), COVID-19 rapid guidelines: severe asthma. [Available from: www.nice.org. uk/guidance/ng166].

13. Shaker MS, Oppenheimer J, Grayson $M$ et al. (2020) Special Article: COVID-19: Pandemic Contingency Planning for the Allergy and Immunology Clinic. JACl in Practice. DOI 10.1016/j.jaip.2020.03.012.

14. World Health Organization Coronavirus disease 2019 (COVID-19) Situation Report [Available from:

https://www.who.int/docs/default-source/ coronaviruse/20200312-sitrep-52-covid-19. pdf?sfursn=e2bfc9c0_2].

15. Zhang JJ, Dong X, Cao YY, Yuan YD, Yang YB, Yan YQ, et al. Clinical characteristics of 140 patients infected with SARS-CoV-2 in Wuhan, China. Allergy. 2020. 